\title{
Rational prescribing in community palliative care
}

\section{SUMMARY}

Palliative care is the province of everyone, particularly people managing older patients.

Most people die of multimorbidity, frailty and dementia rather than cancer and will never see a palliative care specialist.

People dying from non-malignant disease have symptoms and problems that are usually predictable. Common symptoms like pain and dyspnoea can be anticipated. Planning to prevent them, or for when they occur, is more effective than waiting until they happen.

Deprescribing is an effective way of preventing morbidity in this group.

Getting to know a few medicines well for each symptom is important when providing palliative care for patients. Starting at low doses and increasing slowly is also key.

\section{Geoffrey Mitchell (iD}

Emeritus professor, Mayne Academy of General

Practice, University of Queensland, Brisbane

\section{Keywords}

deprescribing, end-of-life care, palliative care, primary care

Aust Prescr 2021;44:45-8 https://doi.org/10.18773/ austprescr.2021.001

\section{Introduction}

By $2050,25 \%$ of the Australian population will be over 65 years of age.' Between 2012 and 2061, the number of deaths per annum will rise by about $250 \% .^{2}$ As the mortality of many previously fatal conditions has been reduced, a large proportion of deaths are due to dementia, multimorbidity, or frailty (or a combination of these). ${ }^{3}$

The way we think of managing dying has to change. At present, specialist palliative medicine covers deaths from cancer and very complex non-malignant conditions. In specialist palliative care services, $80 \%$ of the patients die of cancer ${ }^{4}$ and yet only $20 \%$ of people over 70 die from cancer. ${ }^{3}$ Hence, the burden of care of most dying patients falls elsewhere - in general practice, aged-care facilities and in general inpatient medicine.

Generally, people with life-limiting, non-malignant, multimorbid conditions die in predictable ways. However, the timeframe is very uncertain and can often take years. To better manage end-of-life care for these patients, planning is needed for when acute events happen, rather than reacting to events when they have already happened. This is termed anticipatory care or advance care planning. ${ }^{5}$

\section{Advance care planning and deprescribing}

Quality of life needs to be the primary goal of management for people who are near the end of life. Polypharmacy can impede quality of life through adverse drug effects and drug-drug interactions. Enacting a deprescribing strategy is an important first step (Box). ${ }^{6}$ The physician needs to ask if each medicine maintains current wellbeing or prevents symptoms. In a frail older person there is little place for drugs like statins ${ }^{7}$ which aim to prevent long-term cardiac or neurological events.

\section{Medicines at the end of life}

Much of palliative care management is nonpharmacological. Understanding and incorporating the patient's beliefs and wishes, along with good nursing care, are cornerstones of end-of-life care. Paying close attention to the carer's needs will also help facilitate a satisfactory conclusion to the patient's life. ${ }^{8}$

Evidence-based palliative care treatments, generally derived from people with cancer, are usually applicable to symptoms arising from non-malignant diseases.

\section{Box A deprescribing strategy in frail older people at risk of dying in the foreseeable future ${ }^{6}$}

\footnotetext{
1. Define care goals in the context of life expectancy, functional incapacity, quality of life, and patient and caregiver priorities

2. Ascertain all drugs taken

3. Identify patients at high risk of, or already experiencing, adverse drug reactions

4. Determine disease-specific benefit-harm thresholds that may support treatment discontinuation

5. Review the relative use of individual drugs

6. Identify drugs that may be discontinued or have their dosing modified

7. Implement and monitor a revised therapeutic plan with ongoing reappraisal of drug use and patient adherence
}

Adapted from reference 6 
Australia's Pharmaceutical Benefits Scheme (PBS) has a palliative care section that lists treatments not on the general scheme. These medicines are often available in larger quantities than normal. Comprehensive information on the medicines available and their use is available in Therapeutic Guidelines, Palliative Care. ${ }^{9}$

\section{Pain}

Approximately $70 \%$ of cancer patients experience pain, as do many of those with non-malignant disease. Understanding the nature of the pain is critical in controlling it. Pain that arises from tissue damage (nociceptive pain) usually responds to simple analgesia and opioids. By contrast, pain from nerve compression, infiltration or destruction is often resistant to opioids.

Persistent pain requires regular analgesia. Paracetamol, aspirin and non-steroidal antiinflammatory drugs (NSAIDs) should be considered initially, unless the pain is severe on presentation. NSAIDs should be used with caution in older people, particularly as renal impairment, cardiovascular disease, gastric symptoms and hypertension are common. If there are no absolute contraindications, short courses of NSAIDs can be used to reduce pain to a point where regular paracetamol will control it.

\section{Opioid analgesia}

While there is community concern about the use of opioid analgesia, it should not be withheld from people with ongoing, poorly controlled pain. Very lowdose opioids can provide excellent analgesia in frail older people with conditions like chronic osteoarthritic and spinal pain. Drugs such as buprenorphine patches and low-dose sustained-release oxycodone provide analgesia with low exposure to opioids. Co-existing conditions like renal impairment should be considered when dosing opioids, and vigilance to identify potential toxicity is essential.

There is a wide range of opioids available. It is sensible to be familiar with three or four and know their properties well. In particular, it is important to understand the relative potency of the drugs and their route of elimination. The lowest dose of fentanyl patches, for example, is the equivalent of a daily morphine dose of $40 \mathrm{mg}$. Using it in an opioid-naïve patient is likely to cause significant toxicity. However, fentanyl is entirely excreted by the liver, so is a good choice in severe renal impairment.

While tramadol and tapentadol bind to the mu opioid receptors, and thus are classed as opioids, they also work on noradrenaline and serotonin neurotransmitters, and so have widespread adverse effects including life-threatening serotonin syndrome.
Conversion tables and phone apps that allow rapid calculation of equivalent doses of different opioids are available. Examples include the evi-Q opioid dose calculator, ${ }^{10}$ the Australian and New Zealand College of Anaesthetists Faculty of Pain Medicine's Opioid Calculator ${ }^{11}$ and the GP Pain Help app. ${ }^{12}$

\section{Adjuvant therapies}

The amount of opioid analgesia required can be reduced by using drugs that reduce the intensity of the cause of the pain. For example, antispasmodics (e.g. hyoscine) can reduce the impact of an obstructed hollow viscus, like the gut or the ureter. Oral steroids and NSAIDs can reduce the oedema associated with a hollow viscus obstruction and are widely used in palliative care. Dexamethasone has less propensity to cause adverse effects than prednisolone, but long-term use leads to adverse effects. Infusions of bisphosphonates (e.g. pamidronate or zolendronic acid) can prevent pain from bony secondary tumours and lower the risk of fractures. They are also used to reverse hypercalcaemia.

\section{Neuropathic pain}

Neuropathic pain is frequently resistant to simple analgesics and opioids and requires adjuvants. One antiepileptic drug, pregabalin, is approved for neuropathic pain treatment. However, the dose range is enormous. Much of the neuropathic pain in older people will be managed with quite low doses. To minimise the risk of adverse effects, pregabalin should be started at the lowest possible dose of 25 mg twice a day, and slowly titrated upwards over several days. Antidepressants, particularly low-dose tricyclic antidepressants like amitriptyline, are very useful in this situation. Similarly, a slow titration (from a minimum of $10 \mathrm{mg}$ daily to a maximum of $75 \mathrm{mg}$ daily) is essential to minimise adverse effects. ${ }^{9}$

\section{Dyspnoea}

Dyspnoea, the sensation of breathlessness, may or may not be associated with hypoxia. Chronic and acute severe dyspnoea are very distressing. Simple measures like sitting the patient up, and directing a fan onto their face or opening windows improve dyspnoea. Breathing techniques as taught by physiotherapists, and psychological therapies can be very useful. Oxygen can be used in hypoxic dyspnoea, but is no better than air in treating the sensation of chronic dyspnoea. ${ }^{13}$

Sometimes drugs are necessary. Opioids have strong evidence of reducing chronic dyspnoea, ${ }^{14,15}$ and do not cause respiratory depression if introduced at low doses. Morphine sulfate pentahydrate (Kapanol), a long-acting preparation, has recently been listed on the PBS for chronic dyspnoea. 
Acute episodes can be settled rapidly with sublingual lorazepam 0.5-1 mg. This is one situation where a low dose of continuous benzodiazepines may be warranted.

\section{Nausea and vomiting}

Nausea and vomiting should be addressed promptly. A number of treatments are available in the community, notably metoclopramide and oral haloperidol. While evaluating the cause of the nausea and treating it directly is important, haloperidol $1.5 \mathrm{mg}$ over 24 hours is effective regardless of the cause. ${ }^{16}$ Methotrimeprazine is effective ${ }^{17}$ but is only available through the Special Access Scheme. However, some public hospital services will have it.

\section{Constipation}

Constipation is ubiquitous in frail older people due to limited diet, reduced peristalsis, weakened musculature and the frequent use of opioids and anticholinergic drugs. ${ }^{18}$ Avoid fibre supplements as reduced peristalsis rather than lack of fibre is the principal cause. Stimulant laxatives (e.g. senna, bisacodyl) enhance peristalsis. The osmotic laxative macrogol is effective and widely used.

\section{Confusion and delirium}

Non-drug approaches such as low lighting, familiar surroundings and people (in small numbers) are very effective in reducing the impact of confusion and delirium. Once treatable causes have been excluded, oral or subcutaneous benzodiazepines such as clonazepam (oral or subcutaneous) or midazolam (subcutaneous) can be used to reduce the anxiety. Atypical antipsychotics and haloperidol worsen the symptoms of delirium compared with placebo and have additional adverse effects. ${ }^{19}$

\section{Fatigue, anorexia and weight loss}

Fatigue, anorexia and weight loss are very common in dying patients, particularly those with dementia or advanced cancer. Patients and their carers need to understand that these are inevitable consequences of advanced cancer and are not because of starvation. More food, or nutritional supplements, do not reverse the problem. Some medicines can be tried if these symptoms are causing significant distress. However, multiple medicines have been tried with partial success at best. Steroids can improve appetite but are associated with a large dropout rate due to adverse effects like hyperglycaemia and gastrointestinal bleeding. ${ }^{20}$ Progestogens can increase appetite and weight but carry an increased risk of oedema and thrombotic events. ${ }^{21}$ About a quarter of people with end-stage cancer-related fatigue will experience improvement with methylphenidate. ${ }^{22}$

\section{Conclusion}

Most end-of-life care in the community will be delivered by primary care and other non-specialist medical services. Anticipating likely complications and planning for them is the key to high-quality palliative care. Medicines can be very useful in minimising symptoms, but should be used at low doses with regular patient monitoring. Anticipation of symptomatic needs, and early decisive treatment can minimise the impact of symptoms in older people suffering non-malignant disease at the end of their life. $\varangle$

Conflicts of interest: none declared

\section{REFERENCES}

1. Australian Institute of Health and Welfare. Australia's changing age \& gender profile. In: Older Australia at a glance. 4th ed. Last updated 10 Sep 2018. https://www.aihw.gov.au/ reports/older-people/older-australia-at-a-glance/contents/ demographics-of-older-australians/australia-s-changing-ageand-gender-profile [cited 2021 Mar 1]

2. Australian Bureau of Statistics. Population Projections, Australia, 2012 (base) to 2101. Canberra: ABS; 2013 https://www.abs.gov.au/AUSSTATS/abs@.nsf/ Lookup/3222.0Main+Features12012\%20(base)\%20to\%20 2101?OpenDocument $=$ [cited 2021 Mar 1]

3. Gill TM, Gahbauer EA, Han L, Allore HG. Trajectories of disability in the last year of life. N Engl J Med 2010;362:1173-80. https://doi.org/10.1056/NEJMoa0909087

4. Australian Senate, Community Affairs References Committee. Palliative care in Australia. Canberra: Commonwealth of Australia; 2012. https://www.aph.gov.au/ parliamentary_business/committees/senate/community_ affairs/completed inquiries/2010-13/palliativecare/report/ index [cited 2021 Mar 1]

5. Mitchell GK. The role of general practice in cancer care Aust Fam Physician 2008;37:698-702.

6. Scott IA, Gray LC, Martin JH, Mitchell CA. Minimizing inappropriate medications in older populations: a 10-step conceptual framework. Am J Med 2012;125:529-37 e4. https://doi.org/10.1016/j.amjmed.2011.09.021
7. Liacos M, Page AT, Etherton-Beer C. Deprescribing in older people. Aust Prescr 2020;43:114-20. https://doi.org/10.18773/ austprescr.2020.033

8. World Health Organization. Palliative care. https://www.who.int/news-room/fact-sheets/detail/ palliative-care [cited 2021 Mar 1]

9. Palliative care. In: eTG complete [digital]. Melbourne: Therapeutic Guidelines Limited; 2020. www.tg.org.au [cited 2021 Mar 1]

10. eviQ. Opioid conversion calculator. Cancer Institute of New South Wales; 2020. www.eviq.org.au/clinical-resources/ eviq-calculators/3201-opioid-conversion-calculator [cited 2021 Mar 1]

11. Faculty of Pain Medicine, Australian and New Zealand College of Anaesthetists. Opioid calculator. 2019. www.opioidcalculator.com.au [cited 2021 Mar 1]

12. GP Pain Help app. Brisbane: Queensland Health, Centre for Palliative Care Research and Education. http://www.gppainhelp.com/Title.html [cited 2021 Mar 1]

13. Abernethy AP, McDonald CF, Frith PA, Clark K, Herndon JE 2nd, Marcello J, et al. Effect of palliative oxygen versus room air in relief of breathlessness in patients with refractory dyspnoea: a double-blind, randomised controlled trial. Lancet 2010;376:784-93. https://doi.org/10.1016/ S0140-6736(10)61115-4 
14. Abernethy AP, Currow DC, Frith P, Fazekas BS, McHugh A, Bui C. Randomised, double blind, placebo controlled crossover trial of sustained release morphine for the management of refractory dyspnoea. BMJ 2003;327:523-8. https://doi.org/10.1136/bmj.327.7414.523

15. Currow DC, McDonald C, Oaten S, Kenny B, Allcroft P, Frith P, et al. Once-daily opioids for chronic dyspnea: a dose increment and pharmacovigilance study. J Pain Symptom Manage 2011;42:388-99. https://doi.org/ 10.1016/j.jpainsymman.2010.11.021

16. Hardy J, Skerman H, Glare P, Philip J, Hudson P, Mitchell G, et al. A randomized open-label study of guideline-driven antiemetic therapy versus single agent antiemetic therapy in patients with advanced cancer and nausea not related to anticancer treatment. BMC Cancer 2018;18:510. https://doi.org/10.1186/s12885-018-4404-8

17. Hardy JR, Skerman H, Philip J, Good P, Currow DC, Mitchell G, et al. Methotrimeprazine versus haloperidol in palliative care patients with cancer-related nausea: a randomised, doubleblind controlled trial. BMJ Open 2019;9:e029942. https://doi.org/10.1136/bmjopen-2019-029942

18. Clark K, Currow DC. Assessing constipation in palliative care within a gastroenterology framework. Palliat Med 2012;26:834-41. https://doi.org/10.1177/0269216311414756
19. Agar MR, Lawlor PG, Quinn S, Draper B, Caplan GA, Rowett D, et al. Efficacy of oral risperidone, haloperidol, or placebo for symptoms of delirium among patients in palliative care: a randomized clinical trial. JAMA Intern Med 2017;177:34-42. https://doi.org/10.1001/jamainternmed.2016.7491

20. Miller S, McNutt L, McCann MA, McCorry N. Use of corticosteroids for anorexia in palliative medicine: a systematic review. J Palliat Med 2014;17:482-5. https://doi.org/10.1089/jpm.2013.0324

21. Ruiz Garcia V, López-Briz E, Carbonell Sanchis R Gonzalvez Perales JL, Bort-Marti S. Megestrol acetate for treatment of anorexia-cachexia syndrome. Cochrane Database Syst Rev 2013:CD004310. https://doi.org/10.1002/14651858.CD004310.pub3

22. Mitchell GK, Hardy JR, Nikles CJ, Carmont SA, Senior HE, Schluter PJ, et al. The effect of methylphenidate on fatigue in advanced cancer: an aggregated $\mathrm{N}$-of-1 trial. J Pain Symptom Manage 2015;50:289-96. https://doi.org/ 10.1016/j.jpainsymman.2015.03.009

\section{FURTHER READING}

Li K, Brown M. Prescribing in renal supportive care. Aust Prescr 2020;43:57-60. https://doi.org/10.18773/austprescr.2020.004
Mitchell GK, Johnson CE, Thomas K, Murray SA. Palliative care beyond that for cancer in Australia. Med J Aust 2010;193:124-6. https://doi.org/10.5694/j.1326-5377.2010.tb03822.x 